\title{
MODOS DE SUBJETIVAÇÃO E PRÁTICAS DE GOVERNAMENTALIDADE DESCOLONIZADAS OU DE COMO PRECISAMOS SAIR DA GRANDE NOITE
}

\author{
SUBJECTIVATIVE MODES AND DECOLONIZED \\ GOVERNMENTAL PRACTICES OR HOW WE NEED TO LEAVE \\ THE GREAT NIGHT
}

Alex Sander da Silva Doutor em Educação. Professor do Programa de Pós-Graduação em Educação da Universidade do Extremo Sul Catarinense. E-mail: alexsander@unesc.net

Daiani Barboza Doutora em Psicologia. Professora da Universidade do Extremo Sul Catarinense. E-mail:daianib@gmail.com

\section{Resumo}

Este ensaio se propõe discutir e problematizar conceitos referentes à disputa da dominação colonial no continente africano pós processos de libertação nacional e pensar e suas implicações no Brasil na atualidade. A tentativa diz respeito em pensar as interconexões da dominação colonial pós-libertação em contexto de fluidez da compreensão desses espaços a partir da lógica capitalista. Desse modo, quer se refletir a constituição dos sujeitos e o modo que as práticas de governamentabilidade de si possam ser compreendidas ou não para superação dessa dominação. A proposta diz respeito em aproximarse dos nossos atuais problemas civilizatórios no continente africano e no Brasil, e de sua interferência direta ou indiretamente nas orientações teóricas e práticas a partir de um olhar descolonizado do ponto de vista da própria produção do conhecimento. Nesses termos, colocamos a seguinte problemática: De que modo se situam as ações referentes à disputa da dominação colonial no continente africano e como podemos pensar suas implicações no Brasil, para que se possam construir modos de subjetivação e práticas de governamentabilidade para poder sair da "grande noite"? Nesse sentido, objetivo central do ensaio é analisar os modos como se situam as ações referentes à disputa da dominação colonial no continente africano e como podemos pensar suas implicações no Brasil, para que se possam construir modos de subjetivação e práticas de governamentabilidade para poder sair da "grande noite".

Palavras-chave: dominação colonial, modos de subjetivação; governamentabilidade, descolonização.

\begin{abstract}
This essay aims to discuss and problematize concepts related to the dispute for colonial domination in the African continent after processes of national liberation and thinking and its implications in Brazil today. The attempt is to think about the interconnections of post-liberation colonial domination in a context of fluidity in the understanding of these spaces from the capitalist logic. In this way, it wants to reflect the constitution of the subjects and the way that the governability practices of themselves can be understood or not to overcome this domination. The proposal is concerned with approaching our current civilizing problems in the African continent and in Brazil, and with their direct or indirect interference in theoretical and practical orientations from a decolonized point of view from the point of view of the knowledge production itself. In these terms, we pose the following problem: How are the actions related to the dispute for colonial domination in the African continent and how can we think about its implications in Brazil, so that ways of subjectivation and governance practices can be constructed in order to be able to get out of " big night"? In this sense, the main objective of
\end{abstract}


Revista Tecnologia e Ambiente, v. 27, 2021, Criciúma, Santa Catarina/SC - ISSN Eletrônico 2358-9426 e ISSN Impresso 1413-8131

the essay is to analyze the ways in which the actions related to the dispute for colonial domination in the African continent are situated and how we can think about its implications in Brazil, so that ways of subjectivation and governance practices can be constructed in order to get out of "big night".

Keywords: colonial domination, modes of subjectification; governance, decolonization. 
Revista Tecnologia e Ambiente, v. 27, 2021, Criciúma, Santa Catarina/SC - ISSN Eletrônico 23589426 e ISSN Impresso 1413-8131

\section{Introdução}

A proposta deste ensaio diz respeito em aproximar-se dos nossos atuais problemas civilizatórios, e de sua interferência direta ou indiretamente nas orientações teóricas e práticas, a partir de um olhar descentrado do ponto de vista da própria produção do conhecimento póscolonial. O que isso significa? Significa buscar orientações teórico-metodológicas que possam indicar caminhos formativos de uma nova governamentabilidade coletiva na atualidade, particularmente, das pessoas negras.

Nesse horizonte, cabe algumas questões importantes: Como situar o continente africano no contexto dos problemas contemporâneos, tais como migrações, diversidades culturais, desigualdades sociais e políticas? Como pensá-lo nesse momento em que floresce cada vez mais aspectos de barbárie civilizatória do que de justiça social e emancipação humana no mundo? Que rumos podemos pensar para auxiliar na constituição formativa das subjetividades contemporâneas desde África?

Este ensaio propõe discutir e problematizar conceitos referentes à disputa da dominação colonial no continente africano pós processos de libertação nacional e pensar e suas implicações no Brasil na atualidade. Nesses termos, colocamos a seguinte problemática: De que modo se situam as ações referentes à disputa da dominação colonial no continente africano e como podemos pensar suas implicações no Brasil, para que se possam constituir modos de subjetivação e práticas de governamentabilidade para poder sair da "grande noite"?

A tentativa diz respeito em pensar as interconexões da dominação colonial póslibertação em contexto de fluidez da compreensão desses espaços a partir da lógica capitalista. Desse modo, quer se refletir a constituição dos sujeitos e o modo que as práticas de governamentabilidade de si possam ser compreendidas ou não para superação dessa dominação. A proposta diz respeito em aproximar-se dos nossos atuais problemas civilizatórios no continente africano e no Brasil, e de sua interferência direta ou indiretamente nas orientações teóricas e práticas a partir de um olhar descolonizado do ponto de vista da própria produção do conhecimento.

Nesse sentido, nosso objetivo é analisar os modos como se situam as ações referentes à disputa da dominação colonial no continente africano e como podemos pensar suas implicações no Brasil, para que se possam construir modos de subjetivação e práticas de governamentabilidade para poder sair da "grande noite". Como dito anteriormente, propõe discutir e problematizar ações referentes à disputa de territórios localizados ou simbólicos de dominação colonial e suas implicações no continente africano. Isso significa possibilitar a 
capacidade de abertura, diz respeito em pensar as implicações desses territórios em contexto de fluidez da compreensão desses espaços a partir da lógica capitalista.

O ensaio se configura como a partir de um estudo teórico-analítico que vem sendo realizado, sendo caracterizado como crítico-interpretativo, cuja metodologia se consisti, essencialmente, de pesquisa documental e análise de conteúdo de obras de intelectuais da descolonização, tais como: Leopold Senghor (1964; 1971), Aime Cesaire (1984), Frantz Fanon (2006; 2008, 2013a; 2013b), Achille Mbembe (2001; 2013; 2017); Paulin Hountondiji (1977; 2001), Valetin Mudimbe (2013). As obras e os documentos estão sendo estudados na busca de encontrar conceitos e categorias de análise, tais como: pensamento decolonial, subjetivação, governamentabilidade. O que isso significa? Significa buscar orientações teóricometodológicas que possam indicar caminhos formativos de uma nova governamentabilidade decolonial e coletiva na atualidade em África e no Brasil.

Este ensaio delimita a apresentar resultados parciais dos estudos, limitando a expor algumas reflexões advindas do pensador camaronês Achille Mbembe nas obras Crítica da Razão Negra (2017); Sair da Grande Noite (2013) e do ensaio Necropolítica (2016). Num primeiro momento, vamos fazer algumas observações sobre a obra "Crítica da razão negra", sobretudo, tratamos, sobre o nome "negro" atribuída aos genes de origem africana da era colonial, sobretudo, a partir da ideia do "devir-negro do mundo" apontada por Mbembe (2017). Em seguida trataremos sobre a governamentabilidade decolonial a partir da metáfora do "sair da grande noite" e o significado desse sair relacionando com a questão da necropolítica como política de morte, sobretudo, de corpos negros.

\section{A CRÍTICA DA RAZÃO NEGRA COMO O DEVIR-NEGRO DO MUNDO}

A "descoberta" do pensamento de Achille Mbembe se dá, sobretudo, pelo crescimento dos chamados estudos "pós-coloniais", "descoloniais" ou como alguns preferem chamar "decoloniais". Nossa intenção aqui não discutir essa terminologia, mas pensar a potência criativa e ressignificada advinda do continente africano. Nisso consiste uma dobra no pensamento "habituado", habitado e predominantemente centrado no continente europeu e/ou norte-americano.

Voltar o olhar e a atenção ao continente africano implica alguns movimentos, entre eles poderíamos destacar: reconhecer que não há uma homogeneidade no pensamento no continente. Há sim que situar esse pensamento no seu contexto histórico e qual movimento está se buscando. No caso de Mbembe caracteriza-se como um pensamento que busca uma "autocrítica e pela busca de referenciais endógenos nas ciências sociais e na filosofia para a interpretação 
dos fenômenos observados a partir do próprio continente" (MACEDO, 2016, p. 313).

Outro aspecto de destaque diz respeito ao aumento significativo da "institucionalidade acadêmica, do número de intelectuais de diferentes disciplinas, formações teóricas, políticas e ideológicas, formados parcialmente nos centros de poder intelectual do hemisfério Norte e parcialmente na África” (IDEM, p. 314). As contribuições teóricas e metodológicas dos pensadores africanos, particularmente, da filosofia e das ciências sociais, têm colocado as discussões sobre o pós-colonianismo num outro patamar.

Em seu livro "Crítica da razão negra" o pensador Achille Mbembe faz na introdução da obra um prenúncio, do que ele chama, do "grande acontecimento", ou "a experiência fundamental da nossa época", isto é, afirma que a Europa já não é mais o "centro do mundo". Desse modo, abriu-se novas possibilidades, e novos olhares estão voltados para o continente africano, em que se abre a possibilidade de se repensar a história da humanidade. No entanto, se tem dois caminhos no seu entendimento: por um lado, "pode suscitar perplexidade" ou, por outro lado, "fazer-nos mergulhar num tormento ainda maior" (MBEMBE, 2017, p.9).

Mbembe na introdução do seu livro abre caminhos para o pensar crítico sobre o ser negro, ou aquilo que ele chama de "o devir-negro do mundo". Para o autor, a definição do negro está intimamente associada ao sistema político colonial, uma espécie de nascedouro de um personagem necessário para o funcionamento desse sistema. Um personagem com características próprias para o domínio e espoliação, uma condição de subalternizado para exploração do colonialismo.

Mbembe(2017) faz reconstrução conceitual do ser negro em seu movimento de duplo sentido. Uma espécie de ontologia reversa ou paradoxal que coloca, de um lado, o negro como um não-ser, um nome vinculado as expressões espúrias da condição humana. Por outro lado, o coloca como um significado universal "como signo luminoso da possibilidade de redenção do mundo e da vida num dia de transfiguração" (MBEMBE, 2017 p. 19).

Com sua obra, Mbembe busca fazer uma espécie de deslocamento da imagem do ser Negro de "uma realidade heteróclita e múltipla, fragmentada" (IBIDEM), para uma imagem universal da condição de nós todos nesse momento de crise global. A que isso corresponde? Isso indica que a condição de toda a humanidade submetida aos ditames da era capitalista neoliberal se tornaria a negra, colocada numa espécie de "devir-negro do mundo" (p.21). Deixaria de ser uma mera passagem superável da civilização na construção da igualdade, para se tornar uma forma possivelmente aceitável de lidar com as diferenças e no reconhecimento do outro. Na sua justificativa da obra, Mbembe indica que: 
meio nocturna, tínhamos em mente uma única questão - como pensar a diferença e a vida, o semelhante e o dissemelhante, o excelente e o em comum? A experiência negra resume bem tal interrogação, preservando na consciência contemporânea o lugar de um limite fugaz, de uma espécie de espelho móvel (MBEMBE, p. 21-22).

A esta ideia central no pensamento de Mbembe, está subjacente uma outra: o significado do declínio da Europa no Mundo e a consequente deslocação do centro de gravidade do Mundo para fora desta. Nesse sentido, quando o autor fala do negro como "devir", possivelmente está no horizonte os processos de "descolonização" política, econômica e cultural da África e do resto do mundo. E quando ele fala da libertação dos grilhões da escravização e das lutas anticoloniais que não aconteceu de forma total, justamente porque ainda nos deparamos com constantes situações constrangedoras e humilhantes que ainda insistem em acontecer para as pessoas negras não só do continente africano.

O povo negro carrega a marca da escravidão em seu próprio corpo, no constante apelo de sua autonegação produzida. Para Mbembe, o negro não existe por si só, ele é produzido como necessidade de dominação, isto é, "produzir o negro é produzir um vínculo social de submissão e um corpo de exploração (MBEMBE, 2017, p. 40, grifo do autor). Nessa tendência, teríamos de lidar com uma perspectiva da questão negra relacionada com a "raça". Em termos biológicos o conceito de "raça" não faz sentido, mas isto não impediu que a Europa inventasse as "raças", escolhendo qualquer traço que seja conveniente, como a cor da pele, por exemplo, para classificar os grupos sociais diversos do europeu e se colocar no topo da pirâmide racial.

O conceito de raça ao ser usado com conotação política permite, por exemplo, aos negros valorizar a característica que difere das outras populações e romper com as teorias raciais que foram formuladas no século XIX e até hoje permeia o imaginário popular. O termo raça usado nesse contexto tem uma conotação política e é utilizado com frequência nas relações sociais brasileiras, para informar como determinadas características físicas, como cor da pele, tipo de cabelo, entre outras, influenciam, interferem e até mesmo determinam o destino e o lugar social dos sujeitos no interior da sociedade brasileira.

Desse modo, uma tal devir-negro do mundo está vinculado na chamada "razão negra". Para Mbembe (2017), esta corresponde a um conjunto de "vozes, enunciados e discursos, saberes, comentários e disparates, cujo objeto é a coisa ou as pessoas 'de origem africana' e aquilo que afirmamos ser o seu nome e sua verdade (p.57). A razão negra consiste num conjunto "de discursos como de práticas" que busca conduzir um entendimento do ser negro "enquanto sujeito de raça e exterioridade selvagem, passível de desqualificação moral e de instrumentalização prática" (p.58).

Nesses termos, é importante tratar a questão da razão negra dentro da complexidade do 
racismo. Mesmo as posturas que tem acordo de que "raça" enquanto conceito biológico não exista, ainda não tem consenso no trato com o racismo institucionalizado. Nossa herança escravocrata persiste tão enraizada nos costumes e práticas cotidianas que convém denunciá-la, especialmente, nos locais em que ela se apresenta sem dizer o nome. O raciocínio racista, quando formulado de forma cordial, com sorrisos simpáticos torna-se, particularmente, perigoso, pois domestica a rebeldia, amansa a indignação e enraíza ainda mais essa mentalidade no espírito coletivo. No entender de Mbembe,

(...)o racismo consiste, antes de tudo, em converter em algo diferente, uma realidade diferente. Além de uma força de desvio do real e que fixa afectos, é também uma forma de distúrbio psíquico, e é por isso que o seu conteúdo reprimido vem brutalmente a superfície. Para o racista, ver um negro é não ver que ele não está lá; que ele não existe; que ele mais não é do que o ponto de fixação patológico de uma ausência de relação. É, portanto, necessário considerar a raça enquanto um aquém e um além do ser. É uma operação do imaginário, o lugar onde se encontram as regiões obscuras e sombrias do inconsciente (MBEMBE, 2017, p. 66).

A razão negra está condicionada a uma humanidade castrada, cuja a condição destinada é o da subalternidade. A subjetividade negra esbarra no dado ostensivo da corporeidade cuja avaliação, no entanto, ainda é preconceituosa. Podemos dizer que a cidadania racial, geralmente, mutilada, é emblemático. Os interesses cristalizados, que produziram convicções escravocratas arraigadas, mantêm os estereótipos, que não ficam no limite do simbólico, incidindo sobre os demais aspectos das relações sociais. Na esfera pública, o corpo acaba por ter um peso maior do que o espírito na formação da identidade racial afirmativa.

No segundo capitulo da Crítica da Razão Negra intitulado O poço da alucinação Mbembe afirma que o termo "negro" tem origem ibérica e aparece pela primeira vez escrito num texto em língua francesa no início do século XVI, mas será apenas no século XVIII, auge do tráfico de escravos que seu uso se torna corrente (MBEMBE, 2017, p. 76). O termo está intimamente vinculado a "uma ganga de disparates e de alucinações que o ocidente (e outras partes do mundo) urdiu, e com a qual revestiu pessoas de origem africana muito antes de serem capturadas nas redes do capitalismo emergente dos séculos XV e XVI” (IBIDEM).

Para Mbembe (2017) o negro esta correlacionado com África, uma "relação de coprodução" dos dois conceitos. É com a chegada do europeu ao continente africano que o conceito toma forma, num revestimento externo disseminado para ser inculcado essa enorme "ganga de disparate", cuja função era criar uma "ferida viva que rumina" que produz o ser do outro em sua negação de si. Para ilustrar tal situação, Mbembe traz os autores Franzt Fanon em Pele Negra, Mascaras Brancas que aborda sobre essa ferida e as possibilidades de cura e James Baldwin que trata sobre essa ferida como um veneno, sendo necessário notar o que ele provoca na pessoa que o fabrica e o destila e na pessoa a quem é ministrado (MBEMBE, 2017, p. 77). 
Esse vínculo do "ser negro" a uma enorme gama de "mentiras" e "alucinações" tomou conta das consciências das próprias pessoas negras como um "invólucro exterior cuja função foi, desde logo, substituir-se ao seu ser, vida, trabalho e linguagem” (IBIDEM). Nesse sentido, a imagem do corpo negro que se constituiu ao longo dos tempos por estereótipos atualmente se expressa como formas de violência, que tem um único resultado: a desumanização ou morte dos indivíduos negros. Para Roger Bastide (1973) "a apologia à força física do negro, subentende a ideia de que ele só serve para trabalhos forçados, como a apologia sexual subentende uma opinião pejorativa de sua moralidade".

O corpo negro é marcado por esses estereótipos, para designar a condição de sua subserviência. Nesta perspectiva é interessante notar uma censura psicológica e simbólica para compreender uma corporeidade negada. Nessas condições seu corpo é uma não-presença, uma negação de sua subjetividade humanizada. De modo que, sua identidade, seja ela corporal ou psicológica, é uma conquista demorada e sofrida, formada de heranças e aquisições culturais, de atitudes aprendidas e inventadas e de formas de agir e de reagir.

«Negro»é, antes de mais, uma palavra. Uma palavra remete sempre para qualquer coisa. Mas a palavra tem também uma espessura e densidade próprias. Uma palavra existe para evocar alguma coisa na consciência daquele a quem é endereçada ou que a ouve. Quanto mais densidade e espessura tem, mais a palavra provoca uma sensação, um sentimento e até um ressentimento a quem se destina. Existem palavras que magoam. A capacidade de as palavras ferirem faz parte do seu próprio peso. «Negro» é suposto ser, e sobretudo isso, um nome. Aparentemente, cada nome carrega um destino, uma condição mais ou menos genérica. «Negro» é, portanto, o nome que me foi dado por alguém. Não o escolhi originariamente, herdo este nome pela posição que ocupo no mundo. Aquele que está marcado com o nome «Negro» não se deixa enganar por esta proveniência externa (MBEMBE, 2017, 255-56).

E quando se remete a ideia de um "devir-negro" do mundo, num primeiro momento causa estranhamento e espanto, mas em Mbembe a questão do negro "está ligado a história do capitalismo" (MBEMBE, 2017, p.299). Para ele, o capitalismo tem um "duplo instinto", de um lado, o "da violação ilimitada de todas as formas de interdito e, por outro, "da abolição de qualquer distinção entre meios e os fins" (IBIDEM). E o negro está como produto desse duplo instinto e do que Mbembe chama de " a figura exemplar de uma violência sem limites e de uma precariedade sem limites" (IBIDEM).

O capitalismo avançava rapidamente com seu poder predador para explorar os mais recônditos do planeta. E na visão de Mbembe precisou de "subsídios raciais para explorar os recursos do Planeta" (IBIDEM, grifo do autor). A ideologia racista e exploração capitalista consolidam-se assim num único e mesmo processo, essencial para a formação do próprio capitalismo. E isso é tão presente que o próprio capitalismo não hesita de "colonizar o seu próprio centro, e que as perspectivas de um devir-negro do mundo nunca tenham sido tão evidentes" (IBIDEM, grifo do autor). 


\section{GOVERNAMENTALIDADE DESCOLONIZADAS OU DE COMO SAIR DA GRANDE NOITE}

Podemos dizer que o pensamento de Achille Mbembe se constitui como uma análise crítica da própria condição da vida social do continente africano, no período pós-colonial, sobretudo, azeitado pelo capitalismo avançado, ou naquilo que podemos chamar de sua versão neoliberal. Essa análise se dá, sobretudo, desde o início de sua trajetória profissional em Camarões, passando pelos seus estudos na França e nos Estados Unidos.

Em seu ensaio On the post colony (Sobre a pós-colônia) busca analisar a experiência profunda das sociedades africanas que viveram em regimes coloniais de dominação marcados pela extrema violência exercida nesse período por esse sistema. Para Mbembe, a "pós-colonia" seria uma espécie de "poder bruto" que impregna um determinado controle sobre os sujeitos "herdeiros" do sistema colonial (2001, p. 25). Seria também um gama de signos "partilhado por aqueles que detém o monopólio sobre a vida e a morte, e o sistema de signos quais esse poder se imagina" (MACEDO, 2016, p. 328).

O colonialismo caracterizou-se como um regime de genocídio, usurpação de terras, roubo de recursos naturais que o continente africano sofre suas consequências até os dias atuais (SANTOS; NETO; DIAS, 2019, p.61). Em geral quando Mbembe (2001) se refere ao colonialismo tem em vista as consequências para os colonizados e as distintas formas de violência a que foram submetidos. Mas há um fato que não passa despercebido por Mbembe e que tem a ver com desestruturação das comunidades, ou da chamada unidade nacional, quando seus membros, ou pelo menos grande parte deles, são convencidos, aliciados ideologicamente pela colônia.

Para Mbembe, o pós-colonialismo seria uma espécie de arena de disputas e o seu estudo "assenta, então, no exame das formas de sujeição e das formas de indisciplina que eventualmente possam conduzir a emancipação dos sujeitos" (MACEDO, 2016, p. 328). Desta feita, Mbembe busca renovar as "forças" da luta anti-colonial no campo epistêmico tal como fizeram inúmeros intelectuais africanos, particularmente, em meados do século XX. ${ }^{1}$

Em sua obra Sortir de la grand nuit (2014) (Sair da grande noite) Mbembe apresenta seu programa epistêmico revitalizado para o processo e os desafios da descolonização. Nesse ensaio Mbembe busca mesclar uma narrativa autobiográfica do seu testemunho dos anos de infância em Camarões em que articula dois movimentos que dão a tônica do livro, que são a

\footnotetext{
${ }^{1}$ Importante destacar a obra MACEDO, José Rivair (org.) O pensamento africano no século XX. São Paulo: Outras Expressões, 2016.
} 
metáfora e a literalidade dos temas respectivamente, da "noite e da morte".

No primeiro capitulo intitulado «A partir do crânio de um morto. Trajectórias de uma vida» (pp. 31-48), o próprio autor considera como sendo "um registo deliberadamente narrativo e autobiográfico” (p. 15) que dá o direcionamento da obra. Sua memória ativa de quando era criança recorda "os cadáveres ao relento, revolvidos por escavadeiras; relembra também os revolucionários tornados terroristas pelo discurso do poder colonial, mortos aos quais foi negado o reconhecimento de uma sepultura" (MIGLIAVACCA, 2014, p.560).

[...] escuridão da noite - máscara opaca e, no entanto, tão penetrável - me imbuía, todas as vezes, de um medo indescritível com a sua legião de pirilampos sobre os quais se dizia repetidamente que, em cada um, germinava um fantasma, com os seus cânticos lúgubres de sabor enferrujado, salgados das corrupções da feitiçaria, essa espécie de lapidação, de exaurimento perverso e desmesurado, que resisitia aos destroços do dia e às eras do mundo, com o crânio das cavernas (MBEMBE, 2014, p. 33).

As agudas contradições sociais existentes hoje no continente africano têm caracterizado as condições subumanas de existência de parcela grande da população. O teor político da obra identifica a contradição existente entre a metrópole e a colônia, sobretudo, incrustado nas orientações políticas e sociais do peso do racismo. Mbembe (2014) identifica isso quando ele o destaca a situação das pessoas no continente, mesmo no pós-colonialismo, que ainda vivem no limite das condições de sobrevivência, marcada por profundas desigualdades sociais, seque com poder livre de decisão de escolha política.

Na verdade, é um turbilhão destruidor, imponderado ou brusco, no meio de tantos desastres - ao qual crescem apoquentações inúteis, a improvisação crônica, a indisciplina, a dispersão, o desperdício e um peso de indignidade, desprezo e humilhação ainda mais persistentes do que na época colonial. Na maioria dos casos, os africanos não dispõem sequer da possibilidade de eleger livremente os seus dirigentes (MBEMBE, 2014, p.23).

Além disso, não há como discutir a questão das desigualdades sociais em África sem levar em consideração as condições a que a população negra foi submetida durante o período colonial e as lutas por libertação nacionais. Os grilhões do colonialismo deixaram profundas marcas no continente, no entanto, o debate sobre os processos de libertação não se deu de modo unívoco nas formas de transferência de poder. Mbembe escreve que:

essa transferência de poder é geralmente o fruto de negociações pacíficas e compromissos assumidos entre as elites políticas dos novos países independentes e as antigas potências coloniais, ou uma consequência de uma luta armada para abolir a ascendência estrangeira, resultando na derrota, ou mesmo na evicção dos colonos e na reapropriação do território nacional pelo novo poder autóctone (MBEMBE, 2014, p. 49).

Aqui podemos destacar, a preocupação de Mbembe com os pactos da descolonização.

Certamente, um grande desafio para Mbembe foi buscar entender de que forma o colonialismo ainda opera, a fim de buscar formas de combatê-lo. Desse modo, o pensador camaronês inaugura uma forma de se contrapor ao colonialismo com as forças do próprio continente. Para 
ele, isso será possível com a apropriação conceitual sobre a própria colonização entendida como “uma plena categoria política, polêmica e cultural” (MBEMBE, 2014, p. 49).

Como participante de uma nova geração de intelectuais Mbembe apresenta uma forma original em tratar do tema da decolonialidade. Na sua consideração a Áfricas trata-se de um continente marcado por uma intensa "circulação de pessoas, processos de dispersão e imersão, crioulização e mestiçagem, pela alta capacidade de adaptação e recomposição" (MACEDO, 2016, p.333).

Desde a sua eclosão, esse pensamento foi objecto de interpretações muito diversas e suscitou, em intervalos relativamente frequentes, vagas polémicas e controversas que aliás persistem - e mesmo contestações totalmente contraditórias entre si. Também engendrou práticas intelectuais, políticas e estéticas tão profusas quanto divergentes, a ponto de, por vezes, se questionar acerca dos elementos constitutivos da unidade. Não obstante essa fragmentação, pode afirmar-se que, no seu núcleo central, a crítica pós-colonial visa aquilo que poderia designar-se pela interpolação das histórias e a concatenação dos mundos. Dado que a escravatura, e sobretudo a colonização (mas também as migrações, a circulação das formas e dos imaginários, dos bens, das ideias e das pessoas) desempenhou um papel decisivo nesse processo de colisão e de imbricação dos povos, não é surpreendente que as tenha convertido nos objectos privilegiados dos seus estudos (MBEMBE, 20214, pp. 101-102).

Para isso Mbembe também apostou na crítica daquilo que denominou de necropolítica, ou seja, a política de morte como uma forma de pensar o conceito de biopolitica e biopoder em relação as pessoas negras. Para o autor a expressão máxima da soberania reside, em grande medida, no poder e na capacidade de ditar quem pode viver e quem deve morrer (MBEMBE, 2016, p.123). Seriam formas de compreender as relações de poder numa determinada sociedade.

No ensaio "Necropolítica: biopoder, soberania, estado de exceção, política da morte", Achille Mbembe apresenta uma reflexão sobre esse conceito de necropolítica a fim de indicar o poder e a capacidade de ditar quem pode viver e quem deve morrer (ibidem). Desse modo, Mbembe quer refletir com o conceito de necropolítica na constituição dos sujeitos em sua formulação política e jurídica no interior do Estado. E essa constituição precisa ser compreendidas a partir da herança da dominação colonial que regulamentou e ainda, por algumas formas efetivas e eficazes, regulamenta a vida social ainda hoje.

\footnotetext{
$\mathrm{Na}$ formulação de Foucault, o biopoder parece funcionar mediante a divisão entre as pessoas que devem viver e as que devem morrer. Operando com base em uma divisão entre os vivos e os mortos, tal poder se define em relação a um campo biológico - do qual toma o controle e no qual se inscreve. Esse controle pressupõe a distribuição da espécie humana em grupos, a subdivisão da população em subgrupos e o estabelecimento de uma cesura biológica entre uns e outros. Isso é o que Foucault rotula com o termo (aparentemente familiar) "racismo" (MBEMBE, 2016, p. 128).
}

Desse modo, o fenômeno da colonização é compreendido para expor o poder sobre a vida das pessoas negras, sobretudo, operado naquele período de dominação colonial dos Estados Nacionais sob o domínio de países do continente africano e, posteriormente, nos países que se utilizaram da escravização de pessoas negras africanas. Segundo Mbembe (2016, p. 131), 
as "políticas" feitas por um Estado,

Em primeiro lugar, no contexto da colonização, figura-se a natureza humana do escravo como uma sombra personificada. De fato, a condição de escravo resulta de uma tripla perda: perda de um "lar", perda de direitos sobre seu corpo e perda de status político. Essa perda tripla equivale a dominação absoluta, alienação ao nascer e morte social (expulsão da humanidade de modo geral). Para nos certificarmos, como estrutura político-jurídica, a fazenda é o espaço em que o escravo pertence a um mestre. Não é uma comunidade porque, por definição, implicaria o exercício do poder de expressão e pensamento.

No Brasil, as contradições raciais têm caracterizado as condições de existência de grande parcela da população negra, sobretudo, a que vive no limite das condições de sobrevivência, marcada por profundas desigualdades sociais. Além disso, não há como discutir a questão das desigualdades sociais na sociedade brasileira sem levar em consideração as condições a que a população negra foi submetida após a abolição da escravidão (racismo, miserabilidade, exclusão social de toda ordem).

Os grilhões da escravidão deixaram profundas marcas na história brasileira, no entanto, a dificuldade no debate público sobre os resquícios desta história tem inibido os próprios processos de combate ao racismo. É a experiência escravista um dos caracteres mais significativos que marcaram a história da sociedade brasileira. E nela está pautada a necropolítica que foi estabelecida sobre os negros e as negras brasileiras e se tornou ainda mais aguda porque o Estado, depois da abolição, não implantou políticas públicas especificas para essa parcela da população brasileira. ${ }^{2}$

Os interesses cristalizados, que produziram convicções escravocratas arraigadas, mantêm os estereótipos, que não ficam no limite do simbólico, incidindo sobre os demais aspectos das relações sociais. A invasão pela polícia dos lares favelados e a agressão contra seus habitantes constituem procedimentos rotineiros; são comuns as mortes e os ferimentos de moradores inocentes nos bairros de periferia das grandes e das pequenas cidades. A violência contra a juventude negra, vitimiza os afrobrasileiros em mais de $80 \%$ dos casos (ATLAS DA VIOLENCIA, 2018).

Se tomarmos os dados do Atlas da Violência do Ipea e FBSP ano de 2018 a taxa de homicídios de pessoas negras equivale 2,5 vezes a de não negros. Entre 2006 e 20016 a taxa de homicídio cresceu $23,1 \%$ e entre os não negros teve redução de 6,8. Junte-se a isso as piadas ofensivas; a vigilância redobrada dos seguranças cada vez que se entra num supermercado ou banco; a exploração da figura da mulher negra como "produto de exportação"; a dificuldade de se alugar casa ou conseguir crédito, só para citar alguns exemplos.

\footnotetext{
${ }^{2}$ Conferir o texto "Questões legais e racismo na história do Brasil" de Antônio Carlos Arruda da Silva, nele o autor faz uma breve trajetória de como a estrutura das leis e jurídicas do Brasil calcaram-se na necessidade de manter uma distância entre os "senhores de tudo" e seus serviçais, escravos ou livres. IN: MUNANGA, Kabengele (org.). Estratégias e políticas de combate à discriminação racial. São Paulo: EDUSP: Estação Ciência, 1996.
} 
Figura 1: Atlas da Violencia, 2017

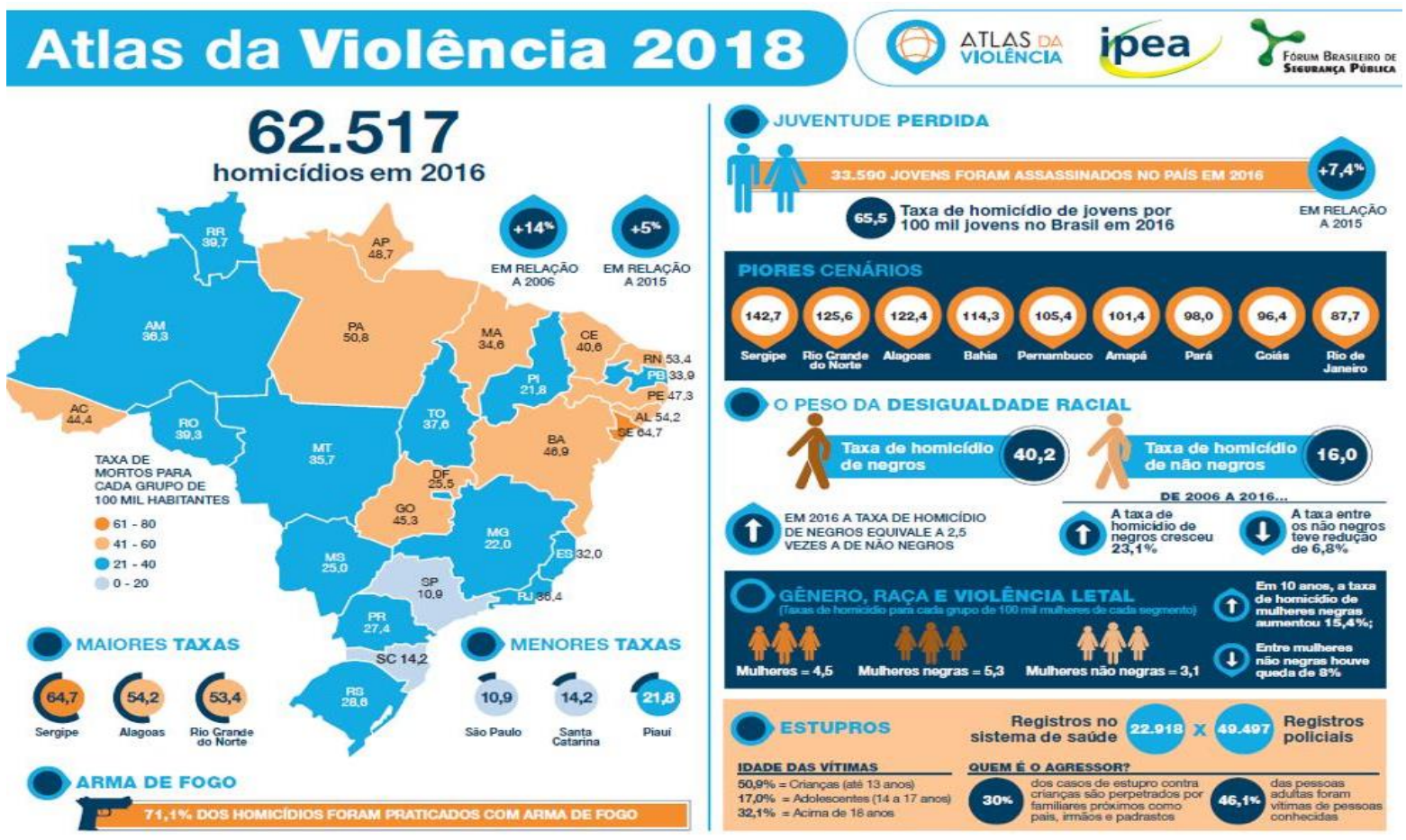

Fonte: https://www.ufrgs.br/epsuas-rs/2018/06/11/atlas-da-violencia-no-brasil-2018-o-que-voce-ja-leu-sobre/

Todavia, se faz importante esclarecer que ser negro no Brasil não se limita às indicações de características físicas. No entanto, a "escolha política" pelo preconceito é definida pela cor da pele e pelo biótipo físico, muitas vezes como dissemos, estereotipado. A discriminação racial precisa ser superada pela discriminação do corpo negro negado nos ambientes onde o negro não aparece (invisibilidade social). Isso tem uma raiz histórica e social a partir do que estrutural daquilo que o movimento negro chamou de "mito da democracia racial".

\section{CONSIDERAÇÕES FINAIS}

A tentativa aqui foi pensar as interconexões da dominação colonial e a compreensão dessa dominação nos dias atuais a partir do pensamento de Achille Mbembe. Seu pensamento se insere num contexto de fluidez da compreensão desses temas a partir da lógica capitalista no continente africano e no mundo. Desse modo, buscou-se se refletir a constituição do pensamento de Mbembe e o modo ele compreende as práticas de governamentabilidade na busca para superação da dominação colonial ainda persistente.

A proposta de Mbembe diz respeito em aproximar-se dos nossos atuais problemas civilizatórios, e de sua interferência direta ou indiretamente nas orientações teóricas e práticas, a partir de um olhar descentrado do ponto de vista da própria produção do conhecimento póscolonial. O que isso significa? Significa buscar orientações teórico-metodológicas que possam 
indicar caminhos formativos de uma nova governamentabilidade coletiva na atualidade, particularmente, das pessoas negras em que a Europa não seja entendida mais como o "centro" do mundo.

Nesse horizonte, cabe algumas questões importantes: Como situar o continente africano no contexto dos problemas contemporâneos, tais como migrações, diversidades culturais, desigualdades sociais e políticas? Como pensá-lo nesse momento em que floresce cada vez mais aspectos de barbárie civilizatória imposta pelo capitalismo neoliberal do que de justiça social e emancipação humana?

Tais questões nos provocam a pensar a indiferença moral em relação ao destino social da população negra ainda tão generalizada. O que há é uma dificuldade nas pessoas em se abalar com a constatação das desigualdades raciais. Mas para além disso temos a tentativa de negação, ou silenciamento da produção cultural, intelectual africana e afro-brasileira. Muito embora estamos gradativamente buscando superar essa condição com o reconhecimento de intelectuais fora do eixo europeu ou norte-americano.

A partir da leitura da obra de Achille Mbembe podemos considerar que seja necessário o reconhecimento que o racismo se aprofunda a partir de uma relação de exploração de classe social. Com efeito, a estereotipia negativa contra o negro e o aprofundamento das diferenças entre os grupos étnicos, ganha novas dimensões, a partir do modo de exploração capitalista. Nesse sentido, não seria exagero considerar que a obra de Mbembe pode ser considerada como espaço que impulsiona a saída daquilo que ele nomeou como "a grande noite".

Num mundo de constantes transformações e de instabilidades, tanto nos aspectos econômicos quanto culturais, decorrentes, sobretudo, do avanço das ciências e das novas tecnologias, a educação assume relevância social de destaque, o que nos exige uma maior compreensão do seu caráter crítico-interpretativo. Para tanto, prescindem pesquisas que possam promover a reflexão sobre os pressupostos e os interesses que estão na base dos conteúdos do seu projeto formativo.

Desse modo, é impossível pensar a educação sem considerarmos sua capacidade de sistematizar experiências cumulativas dos sujeitos, o que permitiria uma compreensão da realidade que ultrapasse o mero uso de esquemas conceituais. Esta proposta de reflexão quer um desvio de rota acadêmico, cujo foco central é estudar o sistema colonial e o deslocamento gerado pelo pensamento decolonial.

No Brasil pós-abolição da escravidão pautou-se em grande medida na ideia da chamada democracia racial. Isso interferiu no modo de como foram tratados os sistemas político, econômico, jurídico e cultural nas relações sociais e raciais brasileiras. Se faz importante 
projetos outros que possa elaborar subsídios teóricos-conceituais, advindos, sobretudo, das experiências metodológicas dos saberes africanos em suas diversidades, como o fio condutor para a luta antirracista no Brasil.

Embora tenha tido grandes avanços no que se refere às lutas dos movimentos negros brasileiro e do povo negro, quanto a aprovação de políticas de combate ao racismo, ainda seguimos com um quadro alarmante de desigualdades raciais na sociedade brasileira. Nesse sentido, podemos dizer que se faz necessário discutir que a luta antirracista requer uma postura conjugada entre os conceitos de raça, classe e democracia. Ou seja, ainda precisamos sair da grande noite do mundo.

\section{REFERÊNCIAS}

AJARI, Norman. De la montée en humanité. Violence et responsabilité chez Achille Mbembe. Revue Unbuntou: revue internationale des sciences humaines et sociales, n. 2013, p. 20-31.

ASHCROFT, Bill et al. The Empire Write Back: theory and practice in post-colonial literatures. London: Routledges, 2004.

BASTIDE, Roger. Estereótipos de Negros através da literatura brasileira. In: Estudos afrobrasileiros. São Paulo: Perspectiva. 1973.

DÉVES,-VALDÉS, Eduardo. O pensamento africano sul-saariano: conexões e paralelos com o pensamento latino-americano e o asiático. Rio de Janeiro: Educam; Clacso, 2008.

FANON, Frantz. Pour la Révolution Africaine. Paris: Éditions La Découverte, 2006.

Pele negra, máscaras brancas. Salvador: Edufba, 2008.

MACEDO, José Rivair (org.). O pensamento africano no século XX. São Paulo: Outras Expressões, 2016.

MBEMBE, Achille. Critica da razão negra. Trad. Marta Lança. Lisboa: Antigona, 2017. Necropolítica. Arte \& Ensaios | revista do ppgav/eba/ufrj |n. 32 | dezembro 2016.

MUNANGA, Kabengele. Algumas considerações sobre "Raça, ação afirmativa e identidade negra no Brasil: Fundamentos antropológicos. Revista USP, n. 68, p. 46-57, dez./fev. 20052006. 